\title{
Praxis reflexiva en los espacios virtuales de formación
}

\author{
Joaquín García Carrasco
}

Universidad de Salamanca, Spaina

\begin{abstract}
Reflective praxis is advocated within the current formative context to the benefit of both the quality of practice and the trainers' own self concept. Action is the main formative tool; it must be understood from its own autonomy and from the representation that teacher educators build upon it. Two main perspectives are offered: the perspective of individual action and the perspective of the action mediated by the inter-subjective relationship and by practice. The reflective praxis becomes an imperative given the cultural contingency posed by the information and communication technologies. The understanding between practices-in and practices-with is differentiated to point out that formative action is always an action mediated by technology. It is also highlighted that it is in the comprehension of practice where the epistemological continuity between theory and practice takes place. Theory provides the rational scaffolding from which the creativity in practices is built.
\end{abstract}

Key words: Reflective praxis. Information and communication technologies

RESUMEN

La praxis reflexiva se reclama, en el contexto actual de la reflexión pedagógica, en beneficio de la calidad de la práctica y en beneficio del propio autoconcepto de los formadores. La acción es la herramienta fundamental de la formación, ha de ser comprendida desde la propia autonomía y desde la representación que los formadores construyen sobre ella. Dos perspectivas fundamentales se ofrecen: la perspectiva de la acción individual y la perspectiva de la acción mediada, mediada por la relación intersubjetiva y mediada por los instrumentos de la práctica. La praxis reflexiva se presenta con más imperiosa necesidad, dentro de la contingencia cultural planteada por las tecnologías de la información y la comunicación. En el documento se diferencia la comprensión entre prácticas-en y prácticas-con, para indicar que siempre la acción de formación es acción mediada por la tecnología. Se subraya que en la comprensión de las prácticas, se produce una continuidad espistémica entre teoría de que dispone el actor y su práctica, así cómo se subraya también que la teoría proporciona el andamiaje racional desde el que se construye la creatividad y la innovación de las prácticas.

Descriptores: Praxis reflexiva. Nuevas technologías de la información y de la communicación.

RÉSUMÉ

La praxis réflexive est réclamée, dans le contexte actuel de formation au bénéfice de la qualité de la pratique y du propre auto-concept des formateurs. L'action est l'instrument fondamental/essentiel de la formation, et doit être comprise à l'égard de l'autonomie et de la représentation que les for- 
mateurs construisent sur elle. Deux perspectives se présentent: la perspective de l'action individuelle et celle de l'action médiatisée, médiatisée par la relation inter-subjective et par les instruments de la pratique. La praxis réflexive se présente, avec besoin impérieux, dans le contexte de la contingence culturelle posée par les technologies de l'information et de la communication. On différence la compréhension entre pratiques-en et pratiques-avec, pour indiquer que l'action de la formation et toujours médiatisée par la technologie. On met en relief que dans la compréhension se produit une continuité épistémique entre théorie et pratique et comment la théorie fournit d'un échafaudage a partir duquel la créativité des pratiques se construit.

Motes-Clés: Praxis reflexive. Le technologie de l'information.

\section{Alarmas en la Práctica de la Formación}

Si tuviera que elegir temas educativos capaces de encender la alarma social señalaría los siguientes: el fracaso escolar, porque agrieta expectativas sociales, hiere orgullos nacionales, dirige el dedo de la acusación hacia un sistema, el de la enseñanza, en el que se encuentran incardinadas parte de la comunidad de personas mejor preparadas, y porque el fracaso escolar agrieta autoconceptos individuales y colectivos; el malestar del profesorado, un síndrome que acumula descontentos, indefensiones, desgaste psicosomático, incremento de ansiedad, una humareda que señala peligrosamente la extensión de un incendio que deja muchos profesores quemados; la desorganización y desestructuración de las relaciones entre los actores en las instituciones de formación (el extremo más alarmante de ese síntoma es lo que se califica de violencia en las aulas), un como si se hubiese desdibujado la percepción del por qué y del para qué de estas instituciones; la dificultad de coordinación de los procesos de formación se dificulta porque los educadores se sienten con la autoridad disminuída, lo que experimentan como una dolorosa alineación y como un sentimiento de extrañamiento en la práctica.

Hoy me parece advertir un nuevo indicio que, aunque sus términos no sean tan alarmantes, entiendo que afectan profundamente a la práctica profesional. Me refiero a la decepción del profesorado. La decepción deja daño más profundo y más difícilmente reparable, precisamente, en quienes alimentaran esperanzas más radicales: alcanza a los ilusionados con ser científicos -semilla que sembró con esmero la institución universitaria-, llega a los que se afiliaron al proyecto de incorporar cultura como medio de mejorar vidas humanas o condiciones de humanidad, alcanza a los más ambiciosos en lo de promover vidas de calidad. Me preocupa especialmente la decepción, porque convive con la sensación de impotencia en los que se sienten más ilusionados, yendo aparejada a un sentimiento de estar apresado en una práctica para la que se sienten capacitados: muchos de los decepcionados se hacen candela de tanto sentirse víctimas. Para convencerse de que los síntomas de alarma pueden llegar a ser puntualmente graves basta ser asiduo lector de prensa y/o conversar frecuentemente con profesores.

Me preocupa también que para aliviar la situación se tome la terapia cómoda de buscar un macho cabrío expiatorio. Algunos toman como "carne de sacrificio" y justificación fácil, a la pedagogía. Dirigen especialmente sus argumentos hacia el denominado naturalismo pedagógico y hacia el activismo didáctico ; del primero critican no dejar constancia de que hay niños y adolescentes en malas condiciones para soportar el proyecto formativo; al segundo, le recriminan no haber resaltado el valor del esfuerzo y 
la disciplina, situando todo el peso de la responsabilidad en la construcción de procedimientos. En una palabra, acusan de los síntomas de alarma a la pedagogía circulante ${ }^{1}$. En este estado de cosas, todos reclamamos participar en las virtualidades innovadoras que contiene la aplicación de las TIC a la enseñanza.

Este trabajo trata de reflexionar, en el horizonte de la sociedad de la información, sobre la práctica de educadores, para que encontremos todos enriquecedor ese oficio y sentirnos en él significativamente enriquecidos. Una autoridad en esto de encontrar ilusión en la tarea de formar, incluso ilusión científica, podría ser Jordi Jordan, profesor de secundaria en Ronda de Lleida, cuya página Web sobre Gaudí ha sido considerada por la Comisión Europea, el mejor recurso de enseñanza en red² ${ }^{2}$ Lo que más me sorprende de este profesor es que defiende los dos principios básicos de los que ha de alimentarse toda pedagogía tecnológica ilusionante: "nunca me conformo sólo con el rigor en las aplicaciones"..."creo que es necesario hacer bellas las cosas, por muy simples, por muy técnicas que sean". No querría tergiversarle, al coincidir en que el artificio básico, el ingenio que la especie sapiens pone al servicio de la incorporación cultural, proceso en el que se juega el más vivir de su descendencia, lo elabora con dos ingredientes fundamentales: rigurosidad en la aplicación de procedimientos y fascinación por la creatividad en la búsqueda de éxito en los objetivos de la formación. La primera proporciona el andamio para la organización del tema y, la segunda, la tenacidad necesaria para el mantenimiento de la rema que sostiene, sin decepcionarse jamás: la búsqueda de la acción posible desde cualquier situación de partida, fundada en el principio de que todos los miembros de nuestra especie, cualquiera sea su condición, necesitan cultura para vivir

Un segundo elemento de las prácticas de incorporación cultural, frecuentemente pasado por alto, es el de que estas prácticas son esencialmente cooperativas. El aspecto cooperativo más repetido es el de la cooperación entre educador y educando; en cambio, la contingencia cultural tecnológica contemporánea, por otro nombre sociedad de la Información, demanda inteligencia social, la necesidad de gestionar la cooperación entre profesores. Los indicios alarmantes anteriormente aludidos, especialmente el de la decepción del profesorado, puede atacarse mediante prácticas colaborativas, porque entiendo que la sensación de aislamiento frente a una práctica problemática puede estar en el origen de la decepción.

En la Universidad Politécnica de Barcelona se ha instalado un Centro de Supercomputación; para él, IBM ha suministrado un superordenador que hace posible la actividad en paralelo de 4.564 microprocesadores. Uno de los más grandes del mundo. No obstante, en muchas universidades la capacidad de computación puede ser aún mayor, si se suman las capacidades de todos los ordenadores de los despachos. M. Valero, director del centro de computación aludido, afirma que el reto tecnológico está en hacer que toda esa capacidad de computación -de que, por ejemplo, las universidades disponen-, pueda ser gestionada al mismo tiempo para un único programa. Este mismo objetivo, el de gestionar la cooperación de los recursos humanos disponibles en vistas a metas compartidas y asumidas como comunes, es el problema en las instituciones de formación: la gestión de la actividad de los agentes intencionales, mediada por 
variados sistemas instrumentales, en beneficio de proyectos cooperativos, en vistas a una significativa incorporación cultural de la generación de alumnos que la sociedad sitúa en las instituciones de formación. El carácter cooperativo de las prácticas toma especial importancia cuando, a las tareas formativas habituales, se añade la demanda de innovación tecnológica que caracteriza a la cultura científico-técnica contemporánea.

Se califica el momento cultural actual como propio de una sociedad de la información. Pero, frecuentemente, se reducen sus notas a las propias del característico desarrollo científico tecnológico. Sin embargo, lo más aparente y próximo de la cultura actual es la velocidad con la que se transforma el conocimiento y la profundidad con la que unos conocimientos se imbrican y condicionan la validez de otros. Como si el principal requerimiento derivado del desarrollo científico y tecnológico actual fuese el de repensar los contenidos culturales que nos son más familiares. Todas estas cuestiones obligan, en el nuevo contexto cultural, a replantearse la actitud racional ante la práctica formativa.

\section{La Comprehension de la Formación Exige Reflexionar Sobre el Significado y el Sentido de la Actuación}

En las narrativas de la formación se dan dos posicionamientos de fondo: el primero confirma que la formación se dirime dentro de relaciones entre el sujeto particular y el mundo, de ahí la importancia concedida a las aptitudes y a las actitudes; el segundo punto de vista, con mayor energía defendido cuanta mayor es la conciencia y la compasión ante la limitación de la condición humana, es el de que la formación postula ante todo oportunidades y situaciones, la mediación de actuaciones y las acciones mediadas por todo tipo de instrumentos. Todavía por debajo de tales posiciones se encuentra el avisado consejo del sentido común. La formación reclama de todos los implicados, acción : se parta de donde se parta, cualquiera sea la condición inicial, la formación es tarea y hay que hacerla, no nos viene de la espontaneidad natural, aunque cuenta con ella. Del sueño ilustrado de un hombre que se hace a solas con el mundo, para construirse mejor, nos despiertan los abandonados supervivientes, los discapacitados, todas las formas de imperfección, todas las ignorancias, todas las dependencias, todas las discapacidades, todas las faltas de motivación para la incorporación cultural. El sentido común deja claro que el proceso de incorporación cultural, aunque responsabiliza individualmente a todos los actores, tiene lugar sin posible escapatoria, dentro de un contexto comunitario de prácticas compartidas. Este es el problema, el dilema y el drama del proceso de formación: la necesaria interferencia de mentes y acciones, la interferencia de las mentes de unos u otros en las actuaciones de unos u otros; en el baturrillo de las prácticas en la comunidad es donde se anulan o se refuerzan las oportunidades y las posibilidades de las operaciones superiores con las que la mente opera (Vygotski 1996): el dar de sí de la gente. En el modelo que piensa la formación como una relación a solas entre la mente y el mundo, la acción que se contempla es, preferentemente, la acción del sujeto particular; en este caso, la del aprendiz. En el modelo que toma la situación como perspectiva preferente, la acción que se considera es una acción medi- 
ada, mediada por relaciones intersubjetivas y mediada por instrumentos, especialmente por instrumentos de comunicación. En el primer caso, se contempla especialmente la acción de la mente en el mundo; en el segundo se discurre, sobre todo, en términos de actuaciones en escenarios de incorporación cultural. Esta diferencia de perspectiva entre acción y actuación queda particularmente puesta de relieve en Leontiev (1984). Como se ve, aunque acción y actuación son términos sobre el mismo asunto, las prácticas humanas, el primero es más abstracto y referido al producto de una competencia; el segundo, lo entendemos más concreto y referido a una competencia que se ejercita en un escenario, formando parte, de algún modo, de una representación.

Precisamente el educador decepcionado es el que pierde la esperanza en la actuación, queda vencido por las circunstancias; desde su real decepción se representa la formación, sorpresivamente, dentro de un idealismo desesperado: la mente, finalmente, anda a solas con el mundo y las hay esencialmente en malas condiciones, respecto a las cuales no parece que haya nada que hacer. Muchos profesores asumen que el problema más grave en la cultura actual es el de que, cada vez más alumnos, no están en las instituciones de formación para lo que deben estar. El caso extremo sería el de los denominados "objetores de la enseñanza". A quien toca esta tragedia, sin poderse zafar, porque en esos escenarios se gana la vida, caso de todos los profesores, el trabajo se convierte en un calvario. Conscientes del riesgo que corro al afirmarlo, creo que aumenta las defensas, no desesperar de la actuación, vivir en la esperanza de que siempre queda un margen de actuación posible. Por eso, la reflexión sobre la propia acción, tiene una virtualidad creativa y cumple, por esta misma vía, una función preventiva y reparadora. Propongo como marco de referencia para considerar esta cuestión tomar la acción-actuación como una pauta que conecta todo el mundo de la vida.

\section{Comprendemos el mundo en términos de actuaciones, causas y consecuencias}

El término acción tiene una textura semántica abierta. En tanto que entidades materiales somos espaciosos; en tanto que organismos, vivimos espaciosamente; en tanto que agentes, todos los seres vivos andan dando de sí y tomándose su tiempo al hacerlo. El espacio pone orden situacional entre acontecimientos simultáneos, el tiempo "distingue el futuro imprevisible del pasado inalterable" (Atkins, 2003: 215); delante, en cada momento y situación, tenemos siempre posibilidad de acción, de actuación en el escenario marcado con parámetros de espacio y de tiempo. Cuando entre acontecimientos del mundo detectamos una secuencia invariante, tendemos a predicar de unos la condición de causas y a atribuir a otros la índole de consecuencias (Bunge 1977, 1978). Somos nosotros, los seres humanos, los que notamos la regularidad, los que construimos la representación ordenada a que dan pie los acontecimientos y los que acomodamos las representaciones que nos formamos de ellos en formatos adecuados, señas o palabras, en vistas a que nuestra experiencia se haga comunicable (Piaget 1934). La inferencia de causas y consecuencias se encuentra en el centro de la experiencia comunicativa; sin este empadronamiento de los acontecimientos, unos en el capítulo de causas y otros en el capítulo de consecuencias, hablaríamos únicamente empleando 
verbos. Toda narración implica la construcción de un ordenamiento causal. También en el caso de la formación, cuya experiencia vivenciamos en términos de éxito o de infortunio, construimos la comprensión dentro de un vendaval reflexivo y narrativo sobre causas y consecuencias de las acciones y las actuaciones. Mejorar la comprensión de los espacios de formación estriba, finalmente, en afinar la reflexión sobre la atribución de causas y de consecuencias. Es la misma estrategia básica que aplicamos a la comprensión del mundo.

Puede comprobarse que al construir narraciones sobre el mundo, a lo largo de la historia cultural, hemos empleado profusamente la estrategia de tratar a todos los entes como si fueran agentes; por este procedimiento tratamos sus procesos como si fuesen secuencias de actuaciones. Aplicamos a los demás entes parecido patrón a aquél con el que construimos los seres humanos las representaciones acerca de nosotros mismos. Esta estrategia interpretativa, de convertir a todos los entes en actores, puede ser denominada, como hace Dennett, enfoque intencional, porque esconde un antropomorfismo subyacente (Dennet 2000: 46), y atribuye a otros entes modos de comportarse que únicamente competen a aquellos agentes intencionales que eligen, toman en cuenta, sienten deseos o tienen pretensiones y creencias. Se representan los cambios en todos los territorios del ser, como si de un proceso de crecimiento y desarrollo individualizado se tratara (Mariner 2004) (Mora 1998); se narran las reacciones bioquímicas entre subsistemas orgánicos, por ejemplo, como acciones de unos agentes sobre otros (Nabau, 1998). Con este enfoque construyeron los seres humanos sus primeras concepciones sobre el mundo, convirtiendo en actores a los elementos cósmicos; la mente infantil emplea parecido procedimiento al elaborar sus primeras interpretaciones y al sentir sus primeros miedos; los antropólogos y los psicólogos han calificado coherentemente este enfoque de "animista".

La ciencia fue abandonando ese enfoque y reduciendo, sobre todo, los fenómenos físicos a su propio ámbito de causas. El enfoque intencional, sin embargo, aun se mantiene en muchos campos fenoménicos, especialmente en el ámbito de las ciencias naturales, como estrategia para la descripción del comportamiento de los animales y de las plantas. F. Waal hace una defensa de esta estrategia metodológica de antropomorfismo, considerándolo un instrumento útil para la comprensión del comportamiento de muchas especies animales, especialmente el de los grandes simios (Waal 2002). Con esas estrategias básicas vamos aplicando la idea de causalidad a todos los fenómenos que afrontamos en la vida, en especial los que acontecen en la mente, privilegiando la intención de los agentes a la hora de considerar las consecuencias de las situaciones. Especialmente acudimos a la intención y a la intencionalidad al tratar de explicar acontecimientos de la formación; situamos la intención de la acción y la intencionalidad del diseño de la actuación en el corazón mismo de una práctica con éxito, en el gozne mismo sobre el que gira su dinámica causal. Por esta legítima vía consideramos que la eficacia de la situación depende de la práctica bien intencionada, de la buena intención de la práctica, de las ganas de tener intención, de tomar la intención con ganas; es decir, asociamos, al menos en principio, la eficacia causal de la práctica formativa a los componentes cognitivos de la intencionalidad y a sus componentes emotivos y motivacionales. Por esta razón, algunos minimizan la eficacia que en la práctica de la 
formación puede derivarse del conocimiento científico sobre los procesos de formación; subrayan que el concepto de causalidad, que vale para poner orden entre acontecimientos del mundo físico, el ámbito de la ciencia y la tecnología, no sirve para poner orden entre actuaciones y consecuencias, ni en el mundo de la vida humana ni en el mundo de las culturas humanas. En ambos casos se entremete el revulsivo de la autonomía imprevisible de los actores. Entre la actuación de un formador y la consecuencia formativa esperada, el vínculo causal se desvanece al quedar interferido por la autonomía del discípulo. Tal vez por este motivo, las narraciones pedagógicas reclamaban docilidad entre las disposiciones requeridas en el discípulo y en el profesor postulaban la fuerza causal de la autoridad.

Según esto, previamente a plantearnos la posibilidad de diseñar prácticas eficaces mediadas por instrumentos, sería conveniente perfilar el significado y el sentido del propio concepto de autonomía, no sea que buscar garantías, en el sentido de eficacia causal, para el éxito de los procesos formativos constituya una quimera. La reflexión en la práctica formativa tiene como marco de referencia fundamental, la mejora de la comprensión de la autonomía. En las reflexiones críticas sobre la situación actual de la educación, la que diagnostica la formación en estado de coma, se alude entre las causas al activismo pedagógico y al fomento sistemático de la actividad autónoma del estudiante, frente a una pedagogía del esfuerzo personal centrado sobre la propuesta del profesor.

\section{Comprender la Formacion Reuiere de Reflexion Sobre el Concepto de Autonomia}

La mediación tecnológica de acceso a la información que aporta el desarrollo científico técnico actual genera un contexto de actividad cultural autónoma sin precedentes, lo que obliga a tomar la autonomía como uno de los conceptos clave del proceso de incorporación cultural.

Antes aludíamos a que en la reflexión humana sobre el mundo se ha empleado con profusión el antropomorfismo como procedimiento narrativo, ahora afirmamos que el estudio de la condición humana se ha servido, frecuentemente, de una reflexión que desconecta al ser humano del resto del mundo de la vida, por ser autónomo. Sin embargo, una característica de la cultura en la Sociedad de la Información está siendo la de encontrar pautas que conectan todo el mundo de la vida. Esto ocurre, precisamente, con el concepto de autonomía, el cual venía siendo exclusivo del ámbito de las ciencias humanas y sociales y, hoy, se extiende por todos los dominios vitales.

Aun cuando en el metabolismo de los organismos encontramos toda la vigencia del mundo de la física y la química (Mosterín 2001), encontramos también en todos ellos una novedad irreductible a la que los biólogos aplican el concepto autopoiesis, de autonomía. La imagen inversa de la autonomía la encontramos en el modo de operar de la computadora con la que trabajo, la cual se moviliza siempre bajo comando. La autonomía en el mundo de la vida, por el contrario, constituye la síntesis de los procesos de autoconstrucción, autogeneración, autorreparación, automantenimiento de la propia estructura, que practican todos los organismos. A través de esos procesos se instituye y confirma una entidad propia, una identidad; de la autonomía emerge la 
autorreferencia respecto a la norma, la autorregulación. En estos sistemas autónomos se pueden definir estados globales, como las motivaciones o las ganas, los deseos o las necesidades. Desde esta autonomía se delimita un medio interno y un medio externo, definido uno y otro con parecida propiedad; tan propio e identitario de cada especie viva es el medio interno como específico es el medio externo, porque tanto uno como otro constituyen o modo de vida o dominio vital de la especie orgánica considerada. De ahí que la autonomía que identifica al ser vivo venga asociada siempre a modos de reconocimiento que también le son propios. Lo que el organismo nota del entorno, y lo que en él adquiere significado, siempre se instituye en función de los procesos autónomos que le definen como identidad. De ahí que la relación con el medio siempre se mira desde un punto de valor, para bien o para mal, de la identidad orgánica: los modos de notar se encuentran acoplados a los modos de vivir, para bien o para mal. $\mathrm{Si}$ el proceso de notar e incorporar del medio lo denominamos información, hemos enseguida de advertir la marcada diferencia entre una dinámica bajo comando y una dinámica bajo principios de autonomía. De ahí que se tenga que marcar la diferencia entre la incorporación de indicaciones (información-1) procedentes del medio, que practican los organismos autónomos, y los procesos bajo comando de tratamiento de las indicaciones (información-2), dentro de la "gestalt del ordenador" (Varela 1989: 11). Esto lleva necesariamente a diferenciar diferentes acepciones del término información, según se aplique a diferentes sistemas intencionales, aun cuando se pueda plantear una teoría general de la información en el máximo nivel de abstracción (Caffarel 1996), en tanto que teoría general de la indicación.

"Cualquier sistema intencional depende de estos modos concretos de pensar (percibir, buscar, identificar, temer, recordar) se piense lo que se "piense" (Dennet, 2000:51).

Por esta particularidad de modos de tratar con las indicaciones, tanto del medio interno como del externo, es por lo que esos sistemas pueden ser influidos, controlados y hasta confundidos, por parte de aquellas entidades orgánicas que puedan acoplar sus patrones dinámicos a los de otros. Con el ordenador podemos cambiar el comando, pero no propiamente confundirlo o engañarlo. Digamos que por el modo de ser es por lo que todos los organismos, especialmente los seres humanos, son tan difíciles de entender; por eso, es tan especialmente intrincado alcanzar lo que verdaderamente entienden de las indicaciones que reciben; el principio de autonomía es el que hace peliagudo entrever y preveer el encadenamiento de causas y consecuencias en las situaciones de práctica social, especialmente en las prácticas sociales de incorporación cultural. El ser humano en su comportamiento es que el que con más radicalidad representa el concepto de autonomía, en tanto que pauta que conecta todo el mundo de la vida.

Todos estos motivos muestran que al introducir el término acción, damos cuenta de la novedad dinámica que instauran los seres vivos desde su autonomía, porque esta dinámica tiene lugar, dentro de la vigencia físico-química de su metabolismo, en un nuevo orden de fenómenos que implican modos de comprensión o equívocos concretos respecto a las situaciones, los modos mediante los cuales son discriminados los objetos 
de su interés, para bien o para mal. En la cúspide de la holarquía de complejidad se encuentra la acción humana y su particular modo de actuar con conocimiento, de instaurar prácticas cooperativas de incorporarse a la acción desde el conocimiento (preconceptos), y para el conocimiento. De ahí la agudeza de Piaget al proponer la comprensión desde la consideración de un conflicto cognitivo.

\section{El tránsito desde la perspectiva de la acción individual a la perspectiva de la acción mediada}

$\mathrm{Al}$ resaltar el concepto de autonomía parece reforzarse la perspectiva, incluso en dominios comunitarios, de interpretarla y remitirla a las acciones individuales, por más que se planteen regularidades y distribuciones estadísticas (Boudon 1982). Dentro de esta lógica, las consecuencias de las acciones de formación se atribuyen causalmente a los individuos particulares. El trabajo de los agentes de formación, dentro de esta ontología, queda en mero auxiliar, función tutora; se facilita la atribución causal a otros agentes, si hay éxito, y se remite íntegra al individuo si acontece el infortunio.

La perspectiva de la acción individual como fuente de explicación de los fenómenos macrosociales no evita considerar que aquella tiene lugar dentro de un sistema de restricciones y virtualidades en las situaciones de práctica (oportunidades), oportunidades más o menos transparentes para el sujeto, las cuales proporcionan también una lógica de la situación. Esta lógica no obliga a pensar en un determinismo mecánico de la socialización, permite tomar en consideración las motivaciones del actor y la conciencia acerca de los medios, desde la que explicita sus márgenes de iniciativa, sus oportunidades y sus preferencias. La acción se posibilita en las situaciones dentro de los márgenes de creencia sobre las prácticas que pueden construir los actores. La comprensión de la acción entre seres humanos ha de situarse, por lo tanto, dentro de esta polaridad entre autonomía y situación de la práctica. Weber subrayaba en el espectador, en primer lugar, la importancia de la comprensión en tanto que observador de las acciones de otros y de las situaciones compartidas, lo que plantea problemas de "distancia cultural" y de opacidad superable de las prácticas, mediante enriquecimiento de información; y, en segundo lugar, resaltaba la relevancia de una actividad de suspensión del juicio, que toma en consideración la posibilidad de equivocarse; lo cual introduce en la comprensión el momento esencial del análisis, la deliberación y la crítica de las propias apreciaciones. Se subraya, por esta vía, tanto el valor de la postura hermenéutica, como el del planteamiento de alternativas de acción resultantes de lo que denominamos intuición (Weber 1974) ${ }^{3}$, condensando en ella todas las formas de inferencia mediante las que elaboramos pensamiento creativo e innovador (Bunge 1986).

La perspectiva en la que la acción se adjudica al actor individual ha sido frecuente y justificadamente transcendida, extendiendo el concepto de acción a la acción colectiva, tomando como actor a los grupos o, en el caso de Marx, a las clases sociales; por esta vía el concepto de acción se aplica incluso a las instituciones (Barrera 2001), a los medios de comunicación social (McQuail, 1998), a las acciones mundiales (UNESCO 1993), incluso en las narraciones de mundos ficcionales aparecen actividades virtuales (García Landa 1998). No es precisamente esa extensión del concepto de acción el asunto más 
importante. El punto decisivo estriba en lo que se encuentra en la raíz de tales transiciones del significado de la acción. En el sustrato de la reflexión sobre la acción en perspectiva individual se encuentra el criterio de que puede analizarse la actividad humana en tanto que interacción directa de la mente particular con los objetos del mundo. Perspectiva que se extrema en toda forma de idealismo, reduciendo la acción paradigmática a su mínima expresión de acto en el proceso de conocimiento (Hegel 1982). En este contexto de reflexión se minimiza la importancia constructiva de las prácticas donde la mente se realiza, y se minimiza la importancia de las mediaciones instrumentales con las que la mente opera.

El titán Piaget, como lo califica J. Bruner, sigue siendo fuente de inspiración para los recientes modelos conexionistas del desarrollo cognitivo, otorga un rol constructivo y enriquecedor a las relaciones entre el niño particular y su ambiente; sin embargo, crecen las críticas sobre los detalles de la secuencia de cambios y sobre la estructura lógicomatemática, caso de Piaget, que se atribuye a éstos (Karmiloff, 1994: 210 ss). El interés de Piaget se centraba en el presente actuacional del individuo, viéndolo ocupado en la asimilación del mundo -ya la metáfora es un indicador de perspectiva- en forma de representación cognitiva; la estructura de ésta se presenta gatillada a la configuración de la acción, estructura de acción a la que el desarrollo ha llevado hasta ese momento; a su vez, la acomodación de la mente al mundo opera por medio de los cambios en el pensamiento que mejor representen el mundo para el sujeto, en su momento de desarrollo (Bruner 1984: 34). El acento individual ha caracterizado durante décadas la investigación en psicología y ha inspirado la narrativa sobre las instituciones de formación. El poderoso trabajo de Piaget se centró en examinar cómo el individuo encuentra significado y sentido en un mundo que se le presenta "genérico", no explorado y común a todo tipo de objetos (Rogoff 1993: 26). No es difícil advertir que esa orientación individual de la reflexión es fuente de inspiración para muchas instituciones educativas y tema de muchas conversaciones entre agentes de la educación.

Frente a la perspectiva individual de la acción se encuentra otra perspectiva complementaria que considera la acción en el proceso real de la vida (Cipriani Thorne 1991); desde este punto de vista se investiga la acción en el marco sociohistórico, centrando la perspectiva en el punto en el que el posicionamiento de la mente es condicionado por la existencia en sociedad.

"Pese a toda su diversidad, la actividad del individuo humano es un sistema incluido en el sistema de relaciones de la sociedad. Al margen de tales relaciones esa actividad no existe en absoluto" (Leontiev 1984: 67).

Dentro de esta perspectiva se toma la acción, no en tanto actividad del espíritu, como en Hegel, sino como "actividad real, objetiva, material del hombre que sólo lo es como ser social práctico” (Sánchez Vázquez 1980: 18). Pero la conquista de tal praxis objetiva, lleva consigo la exigencia metodológica de poner entre paréntesis la concepción que sobre la misma obtiene la conciencia ordinaria, finalmente individualista. Esto es especialmente difícil cuando se encuentra el agente decepcionado de la práctica. 
En la perspectiva sociohistórica, se trata de tomar en la mano la acción, sin abandonar la esperanza, para, desde ella, exigir una explicación.

"El objetivo básico de la aproximación sociocultural a la mente es elaborar una explicación de los procesos mentales humanos que reconozca la relación esencial entre estos procesos y sus escenarios culturales, históricos e institucionales" (Wertsch 1993: 23).

Este planteamiento asume que la acción en contexto social, es la propia y genuina del modo de vida de un ser humano. La historia del pensamiento conecta la propuesta al pensamiento marxista, pero el argumento existencial lo proporcionan todas las catástrofes de niños supervivientes al abandono o las conmociones que se originan desde el abandono, el mal trato o la profunda indigencia material que se acompaña de aniquilamiento moral. En la perspectiva sociohistórica se concibe la práctica como fuente de la regulación de las funciones mentales, es la acción el medio global de expresión y de cambio de la mente humana. La acción en tanto que práctica, praxis, se transforma en unidad de análisis. Frente al estudio de la psique individual se postula un estudio, complementario, de la mente en la cultura, en tanto que su genuino medio de desenvolvimiento (Cole 1999). Esta actitud requiere de confianza infinita en la acción y de compasión infinita respecto a la imperfección. Sin ellas son insostenibles las creencias en la oportunidad para todos y las creencias en que desde cualquier situación de imperfección es posible dar de sí. Esto es equivalente a la creencia en que es propio de la condición humana alcanzar siempre la posibilidad de un desarrollo formativo sostenible, que siempre hay una práctica en la que ese desarrollo sea posible. Esto, en la práctica, pracmáticamente que diría Rorty (1995), supone situar la esperanza en el lugar en el que situábamos exclusivamente al conocimiento.

\section{Las categorías de prácticas}

Podemos, con Habermas, señalar al menos cuatro organizadores para cartografiar el inmenso y rico panorama de la actividad humana. Desde los pensadores griegos, como punto cardinal de las conversaciones, se indica la categoría de acción orientada a metas, seleccionadora de itinerarios, decisora sobre medios, fundada en máximas que representan el diseño de la actividad en vistas al fin pretendido por el agente; este tipo de acción se denomina teleológica (Habermas, 2002); en ella juega un papel dominante el conocimiento disponible, las creencias y la representación del objetivo; el valor de esta categoría de acción se juzga con criterios de verdad y de eficacia. Una segunda categoría de acciones es denominada acción dramatúrgica; en ella, como Goffman (1977) resalta, el actor maneja impresiones y las emociones y los sentimientos proporcionan direcciones de acción, el valor de esta categoría de acción se fundamenta en criterios de sinceridad y autenticidad ${ }^{4}$. La tercera categoría es la que corresponde a la acción regulada por normas, cuyo eje de orientación son los valores compartidos, en ella la calidad se mide con criterios de deliberación sobre el valor y con criterios de observancia al decidir la acción en la situación; esta normatividad no está regida sólo por valores morales, 
sino también por normas asociadas a posición, estatus y roles sociales (Habermas 1991). A todos estos géneros de acción añade Habermas otro que estudia profundamente y que denomina acción comunicativa, una categoría que se orienta a la coordinación de intercambios en vistas al consenso en las interpretaciones; es en ella en la que ocupa un lugar privilegiado la negociación del significado, donde los actores confrontan sus pretensiones de validez en aquellas situaciones que permiten acuerdos. Esta categoría ocupa un lugar de relevancia especial, entrevera y recubre los otros géneros, hasta el punto de que la propia cultura podría ser calificada de sistema clausurado, delimitado, de conversaciones (Maturana 1995).

Pudiera parecer que la perspectiva sociohistórica, especialmente en lo que se refiere a las actividades de formación, hace especial referencia a la acción teleológica, situando la formación en un contexto de actividad técnica; o, por el contrario, que al tratarse de un contexto intersubjetivo, mediado especialmente por el lenguaje, se entendería el proceso de formación como un caso paradigmático de acción comunicativa. Estimo, no obstante, que la acción educativa práctica en contexto social, o acción formativa socialmente mediada, integra todas las categorías y es susceptible de ser analizada desde todas las perspectivas. Por este motivo, preferiré calificarla de acción o actuación en la zona de construcción del sujeto. Acción, si se privilegia la condición de proyecto planificado por uno de los actores para que, entre sus consecuencias, incluya la de progreso formativo; actuación, si tomamos en consideración toda la dramática actuación de todos los actores con rol en el escenario de la formación. Aquí es donde J. Bruner sitúa a otro titán: L. S. Vygotski. Vygotski tomaba la acción de formación en su escenario interactivo. Pero, al mismo tiempo, proponía un programa de investigación sobre la formación de operaciones mentales superiores, tomando en consideración la evolución de las mismas en la historia evolutiva, verlas configurarse como pautas que conectan el mundo de la vida, verlas transformarse en el contexto social de los humanos y verlas promocionarse en la actividad mediada por todo tipo de instrumentos, desde el lenguaje a toda clase se artificios y artefactos. La perspectiva históricosocial no se recluye, como algunos manifiestan entender, en los márgenes sociales s históricos de una comunidad, perspectiva crítica-política, sino que implica para su comprensión integral, la perspectiva evolutiva en el sujeto y la perspectiva evolutiva como sujetos pertenecientes a una especie de entre todas las que conformaron y conforman el mundo de la vida. Esta perspectiva genética, ontogenética, histórica y social forma parte de la aportación cultural de la Sociedad de la Información, en la que tienen tanta relevancia para el significado y el sentido de la cultura las indagaciones sobre el genoma humano como las virtualidades de las innovaciones tecnológicas.

La autonomía del sujeto en la práctica es una autonomía cuya realización se encuentra mediada en la práctica por la relación intersubjetiva, por las virtualidades técnicas que inciden en la zona de mediación, por las posibilidades deliberativas y activas que ofrece el escenario, por la afiliación axiológica de la propuesta formativa. La autonomía no es sólo un punto de partida biopsicológico, sino también un punto de llegada dentro de una comunidad de prácticas sociales. Por este motivo el alumno indispuesto no debe ser la causa de la decepción, porque disponer a la acción se sitúa entre los objetivos prioritarios de la práctica. 


\section{La práctica mediada por instrumentos en la zona de construcción del conocimiento}

Tal vez el aspecto más propio de los representantes del género humano consista en la aptitud para aprovechar la experiencia adquirida por otros dentro de un contexto de interacción estratégicamente diseñado con este objetivo. De hecho, a estos "trucos" relacionales en los que unos incorporan experiencia de otros a su propio patrón de comportamiento es a lo que inicialmente se denominó "cultura", utilizando metafóricamente la pericia del cultivo y el cuidado, del que daban cuenta cabal los hogares agrícolas ( cultura del alma en Cicerón o la geórgica del anima, el trabajo en la tierra del espíritu, en Virgilio).

A este escenario de práctica socialmente mediada es a la que Vygotski denominó zona de desarrollo potencial o de desarrollo próximo. Desarrollo potencial, porque en ella encuentran los humanos el mecanismo mediante el que llevar un poco más allá la aptitud para una tarea, alcanzada desde el desarrollo, incorporando el plus que se obtiene dentro de la interacción cooperativa con otro agente más competente y motivado para la misma práctica. Este potencial es el que ofrece todo escenario de enseñanza y toda práctica cooperativa, ya medie el lenguaje, como en la acción comunicativa, o se lleve a cabo en el interior de cualquier sistema técnico gestionado por agentes intencionales, sean organizaciones laborales o instituciones sociales. Ese plus es el que se investiga y se experimenta en las prácticas mediadas por la tecnología informacional, como ya se exploró en las prácticas mediadas por la escritura, que dieron lugar al aprendizaje generalizado mediante lecciones, fue lo que convirtió en prioridad política de primer orden la generalización social de la competencia lectoescritora y dio lugar a las instituciones de formación. Es también lo que, en la actualidad, cada vez reclama con mayor insistencia el desarrollo de aptitudes para el manejo de las tecnologías informacionales. Siempre digo que se trata de una exigencia de la vigencia de lenguaje, dentro de la vigencia de la escritura, dentro de la vigencia.... No es la vigencia del artefacto, sino la vigencia de las mediaciones instrumentales dentro de la exigencia de incorporación cultural, exigencia propia de la ontología de una mente que se realiza mediante acciones o prácticas mediadas por instrumentos.

De esta condición general del aprendizaje se deriva la inferencia de que la mente de los seres humanos es un sistema natural de desarrollo autónomo, pero social e instrumentalmente promovido. La actividad mental se encuentra indisolublemente asociada a los sistemas de prácticas sociales; en las prácticas sociales, las mediaciones instrumentales (todos los lenguajes, la escritura, todos los instrumentos, todos los artificios), al ser gestionadas por agentes intencionales en vistas a metas, comparten la condición de instrumentos psicológicos, que crean posibilidad y oportunidad para la renovación o transformación de las operaciones mentales. "La tesis central de la escuela culturalhistórica rusa es que la estructura y el desarrollo de los procesos psicológicos humanos surgen por la actividad práctica mediada culturalmente y en desarrollo histórico" (Cole 1999: 106). 


\section{Las prácticas mediadas por la Technología informacional}

Puede haber despistados que pongan el objetivo de las prácticas en el manejo de los artefactos, como podría haberlos que pongan la meta de las lecciones en la universidad en la competencia de los alumnos para tomar notas, o en la del profesor para el manejo de la pizarra. A los sensatos, el nuevo contexto tecnológico les remueve la comprensión acerca de cómo aprendemos, cuáles son las diferencias entre aprendizaje formal e informal, por qué es importante diseñar las prácticas en equipo. La sensatez desconfía de la euforia tecnológica, de la tecnofantasía en los discursos y de la tecnoescatología, de lo resbaladizo que pone el suelo el mercado; pero la sensatez también recupera, por experiencia reflexiva, que la configuración de las prácticas, la acción mediada por instrumentos, es tan importante en cada época histórica, como la presentación cruda del contenido, mediante la comunicación puramente verbal. Estimo que no hay mayor fuente de incomprensiones que la disgregación entre contenido y procedimiento (Salmon 2004). También estimo que no hay perjuicio más grave para la Pedagogía que la obcecación en el procedimiento. La demostración de la investigación pedagógica cabalga sobre su capacidad demostrativa mediante "buenas prácticas". Su sitio más clarificador son las prácticas mediante las que se enseña pedagogía; el escaparate, la pasarela donde se muestra el estado de la pedagogía es el taller en el que la pedagogía acomete la práctica de formar a los formadores.

\section{Significado y sentido de la práctica}

Podríamos definir práctica como una coordinación de acciones que adquiere significado y sentido para el actor/res implicado/s en ella; el significado permite comprender la categoría de actividad (comunicar, intentar una consecuencia), el sentido juzga la plausibilidad y valor del objetivo de la acción, y la coherencia entre su estructura y el propósito.

En el debate entre el idealismo de Hegel y el materialismo dialéctico, Marx proponía el criterio de que si bien toda praxis es acción, no toda acción es praxis (Marx 1974). Ello implicaba no aceptar como perteneciente a la categoría de práctica, toda relación activa entre el sujeto particular y los objetos del mundo. Tan sólo consideraba prácticas aquellas que impliquen transformaciones en elementos (p.e., "materias primas") o en sistemas en los que intervienen elementos materiales. Como analogado principal del concepto de práctica se toma, en este contexto, el sistema trabajo mediado por herramientas, porque sus componentes fundamentales son sujetos corporales, materias primas, productos de transformación e instrumentos de producción. La elaboración de fines o la producción de conocimientos, mientras se mantengan en el ámbito de la conciencia, sin proyectarse en transformaciones históricas, quedarían en el ámbito de la teoría. El marxismo ortodoxo distinguía varios tipos de praxis: la praxis productiva, la praxis artística, la praxis experimental y la praxis política (Sánchez Vázquez 1980: 237ss). Precisamente en esta contraposición entre teoría y práctica se planteaba la confrontación entre los dos sistemas en liza: el idealismo y el materialismo dialéctico. 
Este trabajo, promovido desde la razón vital, sin la necesidad de afiliación al marxismo ortodoxo, como en la situación del espectador orteguiano, considera la vida como quehacer, como historial de acción con significado y sentido; en el contexto histórico social es donde mana la significación, en tanto que compartida, y donde se instituye el sentido, en tanto que participación activa del individuo en la comunidad. El sentido común proporciona una cierta imagen especular de la práctica, cuando afirma: "por sus prácticas los conoceréis". Como si a la complejidad de la identidad correspondiera la complejidad de la práctica; como si, por el hecho mismo de ser conscientes, la verdadera profesión del sujeto humano fuese la del permanente deliberar sobre su práctica, el permanente estar ante ese espejo, como si la práctica fuese el "juego dramático" en el que se expresa la identidad. De esta actitud deliberitiva -"mira lo que estás haciendo", "piensa en lo que haces"-, depende la calidad posible de la práctica productiva, de la estética, de la científica y de la política. Por existir, también la razón vital advierte que, muchas veces, los seres humanos nos vemos empujados a diversas formas dislocación, a una práctica que ha perdido el espejo: aquí el analogado principal es la locura, las prácticas desconcertadas, las prácticas decepcionadas, las prácticas realizadas siguiendo automáticamente su propio diseño previo. Por estos motivos C. Castilla del Pino considera que el megatema del Quijote es la vida y su fábula una teoría biográfica (Castilla del Pino 2005: 60). Hay muchos profesores reclamados por la novedad de las TIC que encuentran en ellas oportunidad y posibilidad para una renovación ilusionante de sus prácticas, la gestión de esta ilusión quijotesca ha de considerarse la parte de responsabilidad, entre otras, que compete en la sociedad de la información a la administración y a la política. Reducir la responsabilidad de la política y de la administración a la aportación de equipamiento minimiza las responsabilidades de la gestión.

Si construimos el concepto de práctica desde la imagen especular construida en la mente, sobre el proyecto de acción posible en las circunstancias dadas, la práctica aparece como una coordinación de coordinaciones, complejidad, de elementos explícitos e implícitos, de elementos que se notan patentes y otros que se notan ausentes.

"Incluye lo que se dice y lo que se calla, lo que se presenta y lo que se da por
supuesto. Incluye el lenguaje, los instrumentos, los documentos, las imágenes, los
símbolos, los roles definidos, los criterios especificados, los procedimientos codi-
ficados, las regulaciones y los contratos que las diversas prácticas determinan
para una variedad de propósitos. Pero también incluye todas las relaciones
implícitas, las convenciones tácitas, las señales sutiles, las normas no escritas, las
instituciones reconocibles, las percepciones específicas, las sensibilidades afinadas,
las comprensiones encarnadas, los supuestos subyacentes y las nociones compar-
tidas de la realidad que, si bien en su mayor parte nunca se llegan a expresar,
son señales inequívocas de la afiliación a una comunidad de práctica y son fun-
damentales para el éxito de sus empresas" (Wenger 2001: 71).

Desde este modo de considerar la práctica los sistemas sociales, como los sistemas de enseñanza, se muestran como "comunidades de práctica"; la condición social humana 
aparece como un radical no poder dejar de participar. Si se afina la pericia en la observación de las comunidades humanas advertiremos que las aspiraciones de identidad, en el espejo de la práctica, se transforman en códigos de oportunidad de practicar y de oportunidad de participar. Desde el espejo de la acción, la profundización en el sentido y el significado de la práctica queda reflejada en código de afán, investigación, estudio, negociación y otras formas de implicación, que lleven a la realización de su sentido, mejor que al infortunio y la decepción. La esperanza en la práctica siempre deja un hueco para la acción posible.

Desde el macroscopio histórico-social que vengo describiendo la práctica proporciona el marco para una experiencia significativa, no dislocada del mundo; con lo que la experiencia de notar el mundo adquiere un sentido realizativo, para bien o para mal, de la propia identidad. Wenger considera que un tratamiento integral de la práctica supone el recorrido de varios itinerarios: la práctica como fuente del significado real, que alimenta la comprensión de la misma por parte de los actores; la práctica, como magma en el que se modula la propia identidad comunitaria, la práctica como zona de construcción del conocimiento y de aprendizaje, la práctica como demarcación y límite entre identidades y como amplificadora-limitadora de oportunidades de identidad, la práctica como situación en la que los acontecimiento del mundo adquieren o pierden sentido, finalmente estaría el trabajo nunca concluso de aprender a comprender la práctica, el trabajo de conocerla mejor y los modos razonables de conseguirlo (Wenger 2001: 74). Sigue estando vigente que los educadores se sostienen o destrozan, se recuperan o decepcionan, se restablecen o se extenúan, en las prácticas. La política de la enseñanza se entiende como gestión colectiva de la oportunidad cultural y como gestión de la posibilidad para la práctica de los agentes intencionales que profesionalmente se implican en ella.

De todos los aspectos considerados, en las cuatro categorías de acciones que extraíamos de Habermas -acción teleológica, acción dramatúrgica, acción sujeta a normas y acción comunicativa-, o en las categorías planteadas por Marx -praxis productiva, praxis artística, experimental o política-, el concepto de actividad práctica cooperativa precisa de la integración, como componentes esenciales de sus diseños, de artificios-artefactos o en la idiosincrasia expresiva del marxismo, de herramientas. Tanto Luria como Vigotski consideraban que el lenguaje debía considerarse como instrumento de los instrumentos (Vygotski, 1982: 287ss). Es razonable pensar, si se toma en consideración que la práctica más propiamente humana es la práctica cooperativa, que la transformación de la situación del mundo en oportunidad de vida de calidad, dentro de nuestra especie, no está en las condiciones del ecosistema ni en la soledad del pensamiento, sino que ha quedado en nuestras manos.

\section{Prácticas formativas mediadas por tecnología (prácticas-con)}

Por este motivo es por el que he defendido (García Carrasco 2001) que las culturas se diferencian en función del sistema comunicacional. Tendríamos culturas de oralidad primaria y culturas derivadas de la contingencia cultural de la escritura; vengo proponiendo la hipótesis de que la tecnología informacional tiene virtualidad técnica sufi- 
ciente para constituir una contingencia cultural, y virtualidad para instaurar un nuevo género cultural, identificado como cultura informacional, por la afectación que la contingencia tecnológica promueve en todo el sistema de la comunicación humana; autores como Poster (1990) y Lotman (1993), refuerzan este criterio de diferenciación a partir de la consideración de prácticas-con sistemas instrumentales de comunicación. Esto supone corregir la perspectiva de algunos autores que proponen diferenciar las contingencias culturales a partir de la emergencia de entornos de prácticas-en: el entorno de la naturaleza, el entorno de la ciudad y el "tercer entorno" emergente desde las tecnologías informacionales (Echeverría 1999). Propongo el análisis, manteniendo la metafórica espacial, pero no desde la perspectiva de práctica-en - prácticas en el espacio virtual-, sino aplicando la perspectiva de práctica-con, prácticas formativas con tecnología informacional. El espacio de acción cambia únicamente en el sentido de que cambian las mediaciones instrumentales de las prácticas. Las culturas serían entendidas como sistemas de prácticas-con (mediadas con sistemas técnicos).

Las tres grandes contingencias antropológicas de la actividad humana están relacionadas con la innovación, bioevolutivamente condicionada, de la aparición del lenguaje, con la innovación técnica de la aplicación de la función gráfica (todas las formas de codificación gráfica sobre superficies) a la comunicación simbólica, y con la innovación de la tecnología digital al tratamiento de la información: esto equivale a proponer que los modos culturales de vida humana han sido especialmente afectados en tanto que sistemas de prácticas realizadas-con mediación lingüística, prácticas-con mediación literaria, prácticas-con mediación informacional.

"El horizonte de expectativas cambia al aparecer un cambio tecnológico por pequeño que sea y esta modificación no se reduce a los efectos que de hecho tenga este cambio, sino que se amplía a cuáles puede tener"(Broncano 2000: 82).

Refiriéndose al lenguaje, Austin afirmaba que hacemos infinidad de cosas hablando, los denominaba "actos de habla" (Austin 1971). La escritura es otra forma de comunicar, no un mero instrumento, o expediente externo de la lengua: un sistema de registro visual del pensamiento sobre superficies manipuladas (Olson 1998); contingencia que modifica la ecología del comportamiento mental, posibilitando nuevos modos de prácticas asociados a la competencia lectoescritora: "pre-textos" y "textos", censos, documentos de identificación, nuevos sistemas de gestión social (p.e. resgistros de contabilidad, registros de propiedad, contratos...), elaboración de tratados sistemáticos, elaboración de árboles conceptuales, , religiones de libro con pretensiones de universalidad, códigos legales, emulación de espacios y de experiencias mediante la creación literaria, nuevos procedimientos de incorporación cultural (la lección, la didáctica, las instituciones de formación, la conectividad entre contenidos que proporciona el manual de la asignatura). Las comunicaciones y las actividades mediante recursos en pantalla es un nuevo género de actividad, que se incorpora a los ya disponibles. Las posibilidades de la tecnología informacional permiten incorporar a los "documentos" elementos multimedia y modos de construcción y presentación de "textos", sistemas de gestión de actividad y comunicación, en contextos de espacio y tiempo, antes no accesibles. 
Aparece una posibilidad de trabajo estructurado en red, que configura modalidades de práctica, cuya gestión debe ser reflexionada desde la comprensión, cuyos objetivos siguen siendo los de la incorporación cultural significativa.

\section{La Praxis Reflexiva el Ejercicio de la Comprehension}

En la vida ordinaria, vamos adquiriendo la comprensión de los acontecimientos, contando - para bien o para mal - con la mano de otros, negociando en la conversación los significados. La comprensión es un ejercicio de conocimiento que se practica mediante acciones de comunicación: lenguajeando en público y/o hablando a solas.

La práctica racional, incluso en el caso de la ciencia, podría sintetizarse como una reflexión, un revolver en la práctica del actuar con conocimiento, un tratar de deliberar sobre garantías a la hora de tratar intelectualmente con los acontecimientos, para cernir y discriminar ilusiones de representaciones válidas.

En los escenarios de formación nos vemos avocados a tratar con acontecimientos: con macroacontecimientos socioculturales y con microacontecimientos interpersonales. Las pretensiones científicas en las prácticas de formación se mueven por el interés de saber si el estudio y la investigación de tales prácticas, aumenta las garantías del proceso de formación: jaumentar la comprensión del mundo de la vida acrecienta nuestra inventiva y la calidad de nuestras estrategias en los escenarios de la formación? ¿̨la habilidad en las prácticas de incorporación cultural se recrece en la medida en que aumentamos la comprensión de lo que está pasando?. A todas luces las situaciones de formación plantean retos desde los contenidos y retos desde las situaciones. Algunos confunden la pedagogía posible con el tener a mano la alucinación tecnológica de hacer hombres por encargo. Esa era la alucinación recreada en la novela de Unamuno "Amor y Pedagogía” (Unamun 1994).

A poco que se observe una situación pedagógica, se adivina en los actores una función de participación en los acontecimientos y otra de representación y explicación de los sucedidos, una función activa y otra reflexiva, una de comprensión y otra de implicación. Las dos formas de pensamiento son imprescindibles, complementarias, hermanas siamesas unidas por el mismo propósito, aunque son "momentos" diferentes de la acción. Muchas veces se ha entendido la formación con un arte; pero, arte especial debe ser, porque el artista se ve comprometido sólo por su propia habilidad en el manejo de sus aparejos -contenidos-; en tanto que el formador se ve comprometido, además, por lo que requiere la situación de los demás actores, no siempre dispuestos en la medida de sus expectativas.

Tanto los historiadores como los educadores tratan reflexivamente con los acontecimientos. Entre acontecimiento y proceso, a mi entender, la diferencia la proporcionan marcas temporales. El acontecimiento está marcado y el proceso se distiende y bifurca en el tiempo con su particular y, a veces, misteriosa deriva. El discurso sobre la formación, la comprensión, se compone de proposiciones relativas a diferentes categorías de procesos y a variadas coordinaciones de procesos. Proceso de aprendizaje es una retícula fractal abierta que sólo marcas arbitrarias de tiempo o límites arbitrales de espacio pueden delimitar, arbitrio que tomamos para interpretarlos razonablemente como "unidades de análisis". Responde este proceder al modo humano de percibir y al modo 
sapiens de experienciar, los cuales son claramente constructivos, realizativos, no de la realidad de las cosas, sino de la categoría objetiva en la que la mente las encapsula a partir de lo que "nota", para hacerlas interpretables y comunicables.

Los acontecimientos con los que bregan el educador y el historiador son diferentes. El historiador ajusta a razón los acontecidos, trata de extraer de ellos, aclarando su flujo caótico, orden y explicación; en ocasiones, la comprensión alcanzada la transforma en advertencia para el futuro. En análogo quehacer están ocupados los antropólogos, sondean las culturas, las describen y comparan, aspirando a encontrar principios que las gobiernen, ambicionando poder formularlos a manera de regularidades, leyes de la cultura.

A poco de conversar con un profesor o con un agente educativo en general, la plática se impregna de enunciados nomopragmáticos: enunciados que aluden a lo que debiera ser, a lo que debiera haber sido o al cómo se debe proceder para que, probablemente, ocurran cosas. En todo caso, la investigación de la educación también es, sobre todo, escrutinio de acontecimientos; pero, a diferencia de la historia, está imbuída de propósito, de creencia en lo que queda por acontecer, de deseo de que algo acontezca. El trabajo en la cultura se funda en que la comunidad cree que está al alcance crear posibilidad y gestionar la oportunidad de que ocurran acontecimientos. La pedagogía se alimenta como campo de conocimiento desde la fascinación por los mecanismos que generan la posibilidad y desde la convicción de que siempre puede quedar a la mano un margen de acción posible. En el fondo, está enraizada en la creencia antropológica de que ser humano es poder dar de sí, cualquiera sea la condición de partida de cada ser humano. Esta convicción es la que protegen las leyes sobre el derecho a la educación o a la igualdad de oportunidades. La pedagogía es experiencia acumulada voluntariosa de que a los sujetos les pasen cosas. La pedagogía investiga cuándo la aspiración se quiebra por falta de oportunidad o posibilidad, y cuando los propósitos naufragan porque los planes estaban equivocados en lo local o en lo global. En el trabajo educativo se toma como presupuesto que, dado un contexto de pasado y el estado de cosas ahora, siempre pueden construirse escenarios nexo con/para un plus de calidad de vida posible. Cuando esta esperanza se quiebra aparecen los educadores quemados o los educadores decepcionados.

Dada la intención del proceso pedagógico, la causalidad a encontrar no puede coincidir con la de las ciencias naturales; en la investigación pedagógica se trata de encontrar la medida en la que la interferencia de la intención, plasmada en planes de acción, p.e. tomar la seña como la lengua nativa para el sordo, puede romper la inercia del decurso de las cosas, p.e. la época en la que el sordo se sumía en la más rigurosa pendiente de deterioro hacia la idiotez. Los itinerarios estratégicos locales pueden variar. La utilidad del conocimiento pedagógico se valora en función de que ocurran acontecimientos. La pedagogía entra dentro de la categoría de conocimiento que busca metas, imbuyendo con ese conocimiento las prácticas comunicativas. Desmenuzar en una narración el "buscar" y el "imbuir" no tiene el rango de un manual de instrucciones. De todo ello se deduce que la teoría de la educación ha de asumir la parte que le corresponde en la fábrica de la teoría general de la comprensión; no puede contentarse con sólo una hermenéutica de la narración sobre los acontecimientos. Dado que la acción 
formativa se discurre mientras acontece la responsabilidad racional de la investigación de la formación, ha de llegar a la hermenéutica de los acontecimientos en construcción: ¿qué es lo que fracasa cuando acontece el fracaso de un niño en la escuela?:qué es lo que fracasa cuando los datos indican fracaso del sistema de enseñanza?`cuándo es legítimo confirmar que el acontecimiento ha sido imposible?

Esta tensión del conocimiento hacia la meta, que alimenta la investigación de las acciones de formación, me confirma en la creencia de que tales acciones pueden clasificarse dentro de la amplísima categoría de los conocimientos técnicos. Porque se trata de un sistema constituído por agentes intencionales, que gestionan procesos, en los que están insertos instrumentos, con la pretensión de que se produzcan acontecimientos. Pero, desde ese mismo momento, adquiere la teoría de la educación, también, la responsabilidad de construir la parte que le corresponde en la fábrica de una filosofía de la tecnología; para que no se produzcan equívocos con quienes hayan construido una filosofía de la tecnología considerando tan sólo la construcción de artefactos o la producción de consecuencias gestionando procesos de manipulación herramientas. La acción que busca metas en educación se estructura como estrategia en contextos de posibilidad, probabilidad, incertidumbre; maneja artefactos, artificios, planes de acción, crea situaciones que generan posibilidad y oportunidad, instituyendo márgenes de acción posible.

\section{La construcción de conocimiento desde la práctica}

No cabe duda de que el contexto de acción humana compartida está permanentemente estructurado a partir de observaciones e interpretaciones. El entendimiento entre los actores no se fragua meramente con los aspectos insólitos o irrepetibles de las vivencias. El entendimiento entre los actores se produce porque, en cierta medida, es compartida la comprensión de los acontecimientos; la comprensión, incluso la más clara y fina, es un entramado de coincidencias en las sorpresas, en las coherencias y en las continuidades, que proporciona la observación. Por este motivo, la prueba de que la observación ha tenido lugar está en que se han producido interpretaciones. Este es el modo específico de notar que tienen los seres humanos. Por el trabajo en la interpretación es por lo que las experiencias son realizativas y no imágenes especulares ni alucinaciones. La coincidencia en el entendimiento de una situación es la primera prueba de que está teniendo lugar un proceso de circulación de significado. Tanto el coincidir como el discrepar verifican que la acción ni fue automática ni fue incoherente, responde a razones y mecanismos que es preciso encontrar, para poder justificar el éxito o el fracaso, dentro de los márgenes reales de acción posible en cada situación. Todos los protagonistas que ofrecen testimonio de su experiencia, dan fe de una experiencia interpretada, de una experiencia de interpretación

\section{El valor racional del testimonio desde la práctica}

El testigo reflexivo, el otro se encoge de hombros, no testimonia sus propias percepciones sino sus relaciones con ellas, no trae en la mano el acontecimiento, ya se perdió por un agujero invisible; cuenta sus relaciones con él, la parte y el modo del aconteci- 
miento que preserva en forma de vivencia su memoria. Da fe de su narración de los hechos, narra los hechos desde su creencia en los acontecimientos. Validar su narración no recupera los acontecimientos. La comprensión de la acción tiene lugar, por esta vía narrativa, dentro de un campo de realidades intermedias, en ese campo de realidades intermedias es donde se sitúa todo testimonio. No son los acontecimientos, las realidades que aportan los testimonios, tampoco ficciones o formalidades. Si se pone la lupa a lo que hacemos podrá comprobarse que el informe científico tiene también el rango de testimonio. Por ese motivo y aplicando idéntico criterio judicial (de relación con el testigo) es por lo que Popper pudo decir que el informe científico (nosotros diríamos que también el testimonio), por ser tal, se incluye en la categoría de conocimientos esencialmente falsables.

El testimonio es la prueba contundente de una competencia humana, no probada en ningún otro ser vivo: la del pensamiento en ausencia, la del pensamiento a una cierta distancia de los hechos. Los seres humanos son rumiantes de representaciones sobre acontecimientos, de las cuales están en condiciones de dar testimonio. Tanto la narración de la observación, como el informe del experimento, ponen en situación de juicio paquetes organizados de interpretaciones, como fase esencial del compartir conocimiento. Con la comunicación testimonial y el juicio sobre las pretensiones de validez de los testimonios, los seres humanos buscan inteligibilidad complementaria para sus prácticas. La valoración judicial de las interpretaciones de las experiencias, expone ante la Audiencia la reflexión, para poder ser sometida a juicio. Si no puede ser enjuiciable, no podrá nunca probar su condición de falsable, nunca podrá ser acreditada como conocimiento con pretensiones de validez, como los estornudos que únicamente alivian a quien tose. En este juicio del testimonio es donde se confrontan las pretensiones de verdad acerca del actuar con conocimiento. La razón humana no sólo juega a actuar con conocimiento, sino que siempre está empecinada en llevar acontecimientos a aquella zona intermedia en la que se practica el juicio. El juicio más elemental es el que comprueba la medida en la que la acción tocó o no tocó diana, el más complicado es el de tratar de explicar los mecanismos mediante los cuales vino a la luz el acontecimiento y los motivos por los que la práctica echó una mano, con éxito o con infortunio.

La vivencia en primera persona, nunca instituye el valor del testimonio; el valor del testimonio lo instituye el componente "judicial" que adquiere en la comunicación, al hacerse público para ser enjuiciado. De ahí que la privacidad con la que frecuentemente se experimentan los acontecimientos de la formación, pone permanentemente en riesgo a los actores: en riesgo de error en la comprensión y en riesgo de decepción ante los acontecimientos.

Cuando se reclama la reflexión en la acción como fuente única del conocimiento pedagógico, se olvida que el testimonio de la misma siempre se ofrece en un "texto" (información oral o documento), aunque se trate de razonamientos sobre probables. El testigo es tomado por Aristóteles más que como narrador de cosas vistas o vividas, como autoridad moral en las que fundar una interpretación. Cuando un testigo se juega la vida en su testimonio, deja de serlo, en opinión de P. Ricoeur, para convertirse en mártir; el verdadero testimonio de quien está dispuesto al martirio no es sobre acon- 
tecimientos, sino sobre la fuerza de su convicción (Ricoeur 1994: 109ss). Por eso, entre otras cosas, la filosofía del testimonio no es otra cosa que filosofía de la interpretación de acontecimientos. Para proceder a la depuración de la interpretación de muchas categorías de acontecimientos, especialmente de acontecimientos de los denominados vitales, circunstancias de la vida, se afinó la Fenomenología; tal vez, la forma de pensamiento más aproximable y hermanable con la ciencia, al menos con las neurociencias (Varela 2002). Por lo tanto el conocimiento en las prácticas de formación ha de llevar a una doble confrontación: con la práctica, mientras transcurre el acontecimiento -aquí se mide con el éxito o el infortunio-; y con la propia interpretación, aquí mide públicamente el testimonio acerca de la interpretación sus pretensiones de validez. La primera deliberación pertenece al ámbito de la experiencia; la segunda, mete la experiencia en territorio de la "ciencia" acerca de las prácticas de formación. ¿Cuáles son las consecuencias lógicas del supuesto de que desde los procesos de formación no puede construirse ciencia, sino únicamente experiencia reflexiva? ¿Qué significa que el margen de racionalidad que deja la práctica reflexiva es únicamente el del pensamiento crítico? ¿Qué es el pensamiento crítico, si no es pensamiento en ausencia, pensamiento sobre interpretaciones de acontecimientos? El testimonio pedagógico inaugura una fase pública en los acontecimientos vividos. La práctica, es ya hermenéutica de primer nivel, la acción de formación es ya pedagogía en estado naciente: conocimiento pedagógico.

\section{Comprehensión de la Práctica Desde la construcción de Prácticas de Formación}

Al profundizar en los procesos de comprensión de las prácticas, mediante el estudio crítico de las interpretaciones, Bruner muestra que la práctica reflexiva incide en un núcleo teórico que denomina "andamiaje" (Bruner 1972) y que muchos educadores califican de "modelo" (Salmon, 2004); este modelo cumple condiciones del concepto de perspectiva, de las de programa de investigación, incluso contiene una aplicación de ámbito restringido del propio concepto de paradigma. En el fondo, responde al núcleo de inteligibilidad, desde el que se genera la práctica en respuesta a la particularidad de las situaciones que afronta el agente. Un mismo núcleo de inteligibilidad puede generar numerosos diseños de prácticas, todas ellas fundamentan sus pretensiones de validez desde el núcleo racional que las justifica. El núcleo es el puente entre la ciencia, racionalidad probada, y la reflexión sobre la complejidad del sistema en el que se prevén consecuencias probables. Estamos ante un modelo teórico, que se justifica racionalmente, y un modelado de la práctica, que se justifica estratégicamente. Aunque suele ocurrir que la concentración de la atención sobre el modelado de la práctica, deja tácito y oculto el núcleo de inteligibilidad desde el que se genera.

La mediación tecnológica, en este caso las herramientas informáticas, como antes fue la escritura y todas sus interfaces en el modelado de las unidades prácticas denominadas "lección", aporta innovadoras virtualidades y posibilidades "para modelar procesos". Reflexionar sobre esta posibilidad de modelado va más allá del mero precipitarse en la interpretación de los discursos de quienes operan con esas mediaciones; requiere de una reflexión sobre la propia producción de formas de práctica, lo que no puede llevarse 
a cabo sin pasar por la propia experiencia creativa que se genera con su empleo (Darely, 2002). No podemos reflexionar sobre la práctica de las aplicaciones tecnológicas, sin practicar, personalmente o en equipo, la inmersión creativa en las mismas; perdería sentido el concepto básico de experiencia reflexiva y perdería sentido el propio concepto de testimonio.

De ahí que pueda ser ilustrativo reflexionar teóricamente sobre un modelo de práctica, para desvelar componentes del núcleo de inteligibilidad subyacente; ese núcleo se instituye, siempre, en generador del andamiaje desde el que se construyen las intuiciones estratégicas que modelan los infinitos formatos de prácticas posibles. Esto ocurre siempre que se actúa con conocimiento; en el otro polo está el actuar desde la alucinación. Podemos tomar, como ejemplo, la obra citada de Salmon, y comprobar que el andamiaje se presenta estructurado en cinco "etapas", cinco arquitecturas de diseño ensambladas, que proceden de un núcleo compartido de inteligibilidad.

La primera tiene que ver con la forma de acceso al propio marco de actividad creado con (prácticas-con) la mediación tecnológica. Aquí las sensaciones de los actores (estados emocionales y aptitudes sociales), respecto a la creencia en el éxito de la práctica, son tan importantes como las habilidades técnicas para su manejo. La mediación lectoescritora creó una cultura de prácticas-con ella, la cual, como todas las culturas, proporcionó seguridades que se remueven al pasar a la nueva mediación tecnológica. Salmon habla de acceso bueno y regular al entorno informático, no basta con que el entorno funcione; la competencia en el manejo de la tecnología debe ir de la mano de la propia realización eficaz de la tarea, para que sean el éxito en la misma y la percepción de su relevancia los reforzadores emocionales de la práctica. La motivación no debe cifrarse en lo espectacular a priori del recurso tecnológico, sino en la relevancia de lo que se alcanza en la propia práctica.

La segunda incide sobre la comprensión del proceso de socialización en el que esta mediación tecnológica se inserta. Salmon recurre a Wenger para sugerir elementos del andamiaje susceptibles de ser atendidos: asumir la práctica de aprendizaje como empresa conjunta entre el e-moderador y los aprendices, practicar la mutualidad para el desarrollo de la aptitud en el manejo de la tecnología y disponer de un repertorio compartido de recursos para la realización de la actividad. De hecho, es observable el crecimiento de la aptitud para el manejo de la tecnología, que los alumnos practican de manera informal en tareas no escolares, crecimiento que motiva el interés por las prácticas y no el interés a priori por el manejo de la tecnología: p.e. se coordinan en los juegos de ordenador, en la comunicación en red, con la puesta a punto y mantenimiento cooperativo de los sistemas, en los intercambios de software, y en la confianza en los servicios mutuos.

La tercera, toma en consideración el valor del intercambio de información en tareas de cooperación y la utilidad derivada de que estos intercambios aprovechen la asincronía que permite la tecnología, tanto para los contactos-consulta como para los intercambios de información pertinente, expandiendo el espacio de ayuda que limita el aula presencial de aprendizaje. Se extiende el tiempo útil de ayuda mutua, sin límite de distancia, para la realización. La tecnología puede hacer accesibles y visibles todos los intercambios entre miembros de la comunidad de aprendizaje, durante el tiempo útil 
de realización de las tareas. El aula expande su espacio en el foro. La tutoría extiende su función en la e-moderación.

La cuarta, recae sobre el reconocimiento que los actores adquieran sobre el hecho de ver enriquecida su capacidad de creación de conocimiento. La práctica-con, en este momento, incluye en su andamiaje el ejercicio de funciones críticas para las operaciones mentales, sobrepasando el cortar y pegar, lo que en otros contextos equivale al aprendizaje memorístico, las respuestas sin justificación, el estudio superficial. En el foro de actividad compartida se multiplican las posibilidades de corrección.

La quinta, permite incidir sobre ámbitos metarrepresentacionales: transferencia de conocimientos a otras situaciones o campos de problemas que un actor puede intuir, o un e-moderador sugerir. Las prácticas-con tecnología de comunicación en línea posibilitan la revisión anticipada de un esfuerzo, antes de la solución definitiva que se propone para su evaluación.

Estas etapas que propone Salmon desde su personal experiencia, pueden reformularse desde otras experiencias. Advierten, que una praxis reflexiva sobre prácticas-con tecnología, requiere de un proceso acumulativo de construcción de experiencia; por esta vía, reproducen el crecimiento de aptitud y habilidad que los actores de la formación adquirieron cuando el espacio de la formación se construyó en un mundo sobre el papel. Ese proceso se inició desde el momento en el que en las propias aulas infantiles la formación arrancó bajo el principio de una acción mediada por la competencia lectoescritora, considerándose desde aquel momento como una necesidad instrumental de la formación.

Las prácticas-con tecnología informacional han de tomar constancia de que la contingencia cultural tecnológica incide sobre los actores de la formación en edades cronológicamente diferentes. La gestión del desarrollo de la aptitud y la habilidad de los formadores en la mediación tecnológica es un reto inaplazable, que el siglo XXI plantea a la pedagogía. Pero hay un dato previo para el ejercicio de la comprensión pedagógica. No podemos desarrollar praxis reflexiva sin asumir la responsabilidad de actores en el nuevo contexto de experiencia. La praxis reflexiva que los pedagogos han de fomentar, tiene como escenario prioritario el espacio en el que los pedagogos enseñan pedagogía, los centros en los que se forman los formadores, para que la práctica-con estas tecnologías se instituyan en el núcleo de inteligibilidad desde el que empiezan a construir el inicio de su experiencia de formadores.

\section{Bibliografía}

Austin, J.L. 1971 v.o. 1962. Palabras y acciones. Buenos Aires: Paidós. Atkins, P. 2003. El dedo de Galileo. Las grandes ideas de la ciencia. Madrid: Espasa Calpe. Baltasar, H. 1995. Teodramática. Vol. 4, "La acción". Madrid: Encuentro.

Barrera Guarderas, A. 2001. Acción colectiva y crisis política: el movimiento indígena ecuatoriano en la década de los noventa. Quito: Centro de investigaciones CIUDAD: Abya-Yala.

Boudon, B.-Bourricaud, F. 1982. art. Action. En "Dictionnaire critique de la Sociologie". París : P.U.F.

Broncano, F. 2000. Mundos ratifícales. Filosofia del cambio tecnológico. Barcelona: Paidós.

Bruner, J.S. 1972. Hacia una teoría de la instrucción. México: UTEHA.

Bruner, J.S. 1984. Acción, pensamiento y lenguaje. Madrid: Alianza. 
Bunge, M. y alt. 1977. Las teorías de la causalidad. Salamanca: Sígueme.

Bunge, M. 1978. Causalidad: el principio de causalidad en la ciencia moderna. Buenos Aires: Editorial Universitaria Buenos Aires.

Bunge, M. 1986. Intuición y razón. Madrid: Tecnos.

Dennet, D. 2000. Tipos de mentes. Hacia una comprensión de la conciencia. Barcelona: Debate.

Echeverría, J. 1999. Los señores del aire: Telépolis y el tercer entorno. Barcelona: Destino.

Caffarel Serra, C. (comp.) 1996. El concepto de información en las Ciencias Naturales y Sociales. Madrid: Ed. Universidad Complutense.

Castilla del Pino, C. 2005. Cordura y locura en Cervantes. Barcelona: Península, Barcelona.

Cirpiani Thorne, B. 1991. Acción Social y mundo de la vida: estudio de Shütz y Weber. Pamplina: Ediciones de la Universidad de Navarra.

Cole, M. 1999. Psicología cultural. Una disciplina del pasado y del futuro. Madrid: Morata.

Darely, A. 2002. Cultura visual digital. Espectáculo y nuevos géneros en los medios de comunicación. Barcelona: Piados.

Envist, I. 2000. La educación en peligro. Madrid:Grupo Unisón Editores.

García Carrasco, J- García del Dujo, A.2001. Teoría de la Educación. T.II. 'Procesos primarios de formación del pensamiento y la acción". Salamanca: Universidad de Salamanca. Especialmente se desarrollan estos planteamientos en el cap. X.

García Landa, J.M. 1998. Acción, relato, discurso: estructura de la ficción narrativa. Salamanca: Ediciones de la Universidad de Salamanca.

Goffman, E. 1997. La presentación de la persona en la vida cotidiana. Buenos Aires: Amorrortu.

Habermas, J. 1991. Escritos sobre moral y eticidad. Paidós, Barcelona (2002). Acción comunicativa y acción sin transcendencia. Barcelona: Piados.

Hegel, G.W.F. 1982. Fenomenología del espiritu. México:F.C.E.

Karmiloff-Smith, A. 1994. Más allá de la modularidad. La ciencia cognitiva desde la perspectiva del desarrollo. Madrid: Alianza.

Leontiev, A.N. 1984. Actividad, conciencia y personalidad. México: Ed. Cartago.

Lotman, I. M. 1993. Consideraciones sobre las tipologías de las culturas. Valencia: Episteme.

Mariner,T. 2004. Tierra en acción. Madrid: Euroimpala Editores.

Marx, C. \& Engels, F. 1974. La ideología alemana: crítica de la novísima filosofia alemana en las personas de sus representantes Feuerbach, B. Bauer y Stirner y del socialismo alemán en las de sus diferentes profetas. Barcelona: Grijalbo.

Maturana, H. 1995. La realidad ¿objetiva o construida?. T. 1. Fundamentos biológicos de la realidad. Barcelona: Anthropos.

McQuail, D. 1998. La acción de los medios: los medios de comunicación y el interés público. Buenos Aires: Amorrortu.

Mora, J. 1988. Acción de las corrientes eléctricas de bajo amperaje en la regeneración ósea. Bellaterra:Universidad Autónoma de Barcelona. (Microfilm).

Mosterín, J. 2001. Ciencia viva. Reflexiones sobre la aventura intelectual de nuestro tiempo. Madrid: Espasa, Madrid. Especialmente, cap. 10 “QQué es la vida?”, pp.149-179.

Nabau Moretó, N. 1998. Acción de la bombesina en el cáncer de colon y páncreas. Universidad Autónoma de Barcelona, Bellaterra (microfilm).

Olson, D.R. 1998. El mundo sobre el papel. El impacto de la escritura y la lectura en la estructura del conocimiento. Barcelona: Gedisa.

Piaget, J. 1934. La causalidad fisica en el niño. Madrid: Espasa Calpe.

Poster, M. 1990. The Mode of Information. Poststructuralism and Social Context. Chicago: The Chicago University Press.

Ricoeur, P. 1994. Lectures 3. Aux frontières de la philosophie. París : Seuil. Cap.

"L'herméneutique du témoignage" (1972), pp.107ss.

Rodríguez Tapia, R. 1999. La enseñanza neutral. Madrid:Grupo Unisón Editores.

Rogoff, B. 1993. Aprendices del pensamiento. El desarrollo cognitivo en el contexto social. Barcelona: Piados.

Rorty, R. 1995. L'espoir au lieu du savoir. París, Albin Michel. 
Rosúa, M. 2001. El archipiélago Orwel. Madrid:Grupo Unisón Editores.

Ruiz Paz, M. 2003. La secta pedagógica. Madrid:Grupo Unisón Editores.

Ruiz Paz, M. 1999. Los límites de la educación. Madrid: Grupo Unisón Editores.

Salmon, G. 2004. E-actividades. El factor clave para una formación en línea activa. Barcelona: Editorial UOC.

Salvador, G. 2004. El destrozo educativo. Prólogo de Antonio Muñoz Molina. Madrid: Grupo Unisón Editores.

San José, A.de 2001. El espacio del profesor. Madrid: Grupo Unisón Editores.

Sánchez Vázquez, A. 1980. Filosofía de la praxis. Barcelona: Crítica-Grijalbo.

Unamuno, M. 1994. Amor y pedagogía. Madrid: Espasa Calpe.

UNESCO 1993. Acción mundiales pro de la educación. París:UNESCO, París.

Varela, F. 1989. Autonomie et connaissance. Essai sur le Vivant. París: Seuil.

Varela, F. 2002 El fenómeno de la vida. Santiago de Chile: Dolmen ediciones

Waal, F. 2002. El simio y el aprendiz de Sushi. Reflexiones de un primatólogo sobre la cultura. Barcelona: Piados.

Weber, M. 1974. Sobre la teoría de las ciencias sociales. Barcelona: Península.

Wenger, E. 2001. Comunidades de práctica. Aprendizaje, significado e identidad. Bercelona: Piados.

Wertsch, J.V. 1993. Voces de la mente. Un enfoque sociocultural para el estudio de la Acción Mediada. Valladolid: Visor.

Vygotski, L.S. 1982. Pensamiento y lenguaje. En “Obras Escogidas”, T.II. Madrid: Visor. Especialmente el capítulo "Pensamiento y palabra":. 287 y ss.

Vygotski, L.S. 1996 v.o. 1976. El desarrollo de los procesos psicológicos superiores. Barcelona: Critica-Mondadori.

\section{Notas}

1. En esa crítica a la pedagogía aparecen no pocos insultos, lo que da a entender que el malestar es verdaderamente profundo, pueden leerse los ensayos que va editando el "Grupo Unisón Editores": Salvador 2004; Ruiz Paz, M 2003; Id.id. 1999; Rosúa, M.; Rodríguez Tapia 2001; San José, A. De 2001; Envist, I. 2000.

2. www.elearningeuropa.info.

La dirección de la página Gaudí: www.xtec.es/ -jjordan/tecno/cts/gaudi/gaudi/htm La Web personal del profesor Jordi Jordan: www.xtec.es/ -jjordan/

3. El estudio de categorías de sociología comprensiva lo desarrolla Weber (1974).

4. Tal vez por este papel del sentimiento es por lo que no sólo proporciona tema para el estudio de las relaciones, sino también para el estudio de la religión. (Baltasar, 1995) 